\title{
Relationships of the Vitamin D and Platelet Indices in Sjögren's Syndrome
}

\author{
Nahide Ekici Günay ${ }^{1}$, İrfan Buğday², Tayfun Akalın ${ }^{3}$ \\ ${ }^{1}$ Department of Clinical Biochemistry, University of Health Science, Kayseri City Training and Research Hospital, Turkey \\ ${ }^{2}$ Department of General Medicine, University of Health Science, Yeşilhisar State Hospital, Kayseri, Turkey \\ ${ }^{3}$ Department of General Medicine, Division of Rheumatology, University of Health Science, Kayseri City Training and Research Hospital, Turkey
}

\begin{abstract}
Primer Sjögren's Syndrome (pSS) is an autoimmune/inflammatory illness. The platelet indices (PIs) indicate the inflammatory response and activity/severity of many diseases. A vitamin D deficiency is accompanied by the increased tendency of autoimmune diseases. This study investigated whether the vitamin D levels are related to the altered platelet indices in pSS. A total of 261 individuals were included in this analytical cross-sectional study. The laboratory data of pSS patients were evaluated and the relationship between the PIs and vitamin D status was examined. According to these findings, in patients with pSS, the vitamin D levels were lower than the healthy control group $(P<0.05)$. The vitamin $\mathrm{D}$ levels were negatively associated with PDW $(P=0.012)$, but positively correlated with PCT $(P<0.001)$. The cut-off point was obtained with receiver operating characteristics (ROC) curves for PDW: 12.53 (AUC 0.921, sensitivity 90\%, specificity $85 \%$ ), for PCT; 0.29 (AUC 0.660 , sensitivity $68 \%$, specificity $55 \%$ ). In multivariate linear regression analysis, the most significant parameters for the effects of PDW are the following: vitamin $D(\beta=-0.373 ; t=-2.626$; sig. $=0.013)$ and plateletcrit $(\beta=-0.308 ; t=-2.13$; sig. $=0.040)$. A vitamin D deficiency may be accompanied by changes in PIs in pSS. A higher PDW and lower PCT supports the underlying inflammation, which may be vitamin $D$ related useful parameters to consider in approaching to pSS.
\end{abstract}

Key words: Plateletcrit, Platelet distribution width, Sjögren's syndrome, Vitamin D

This is an Open Access article distributed under the terms of the Creative Commons Attribution Non-Commercial License (http://creativecommons.org/licenses/by-nc/4.0) which permits unrestricted non-commercial use, distribution, and reproduction in any medium, provided the original work is properly cited.

Copyright $@ 2018$ The Korean Society for Clinical Laboratory Science. All rights reserved.
Corresponding author: Nahide Ekici Günay Department of Clinical Biochemistry, University of Health Science, Kayseri City Training and Research Hospital, Şeker Mah. Molu Cad. 38080, Turkey

Tel: $90-352-315-77-00$

Fax: 90-352-336-88-57

E-mail: edihan30@yahoo.com

Received: September 29, 2018 Revised $1^{\text {st. }}$ October 20, 2018 Revised $2^{\text {nd }}:$ October 31, 2018 Accepted: November 1, 2018

\section{INTRODUCTION}

Although the development and progression of pSS haven't been fully elucidated, it is considered that interactions between immune, genetic and environmental factors play a role in the pSS. It is well-accepted that autoimmune diseases lead systemic inflammation [1]. In Turkey, pSS prevalence has been reported as $0.21 \sim 0.35$ to $0.72 \sim 1.56$, highlighting higher prevalence than those in SLE $(0.04 \%)$ and RA $(0.36 \%)$ in parallel to developed countries [2-5].

Studies on vitamin D levels in autoimmune disorders reported comprehensible results [6]. In recent years, it has been suggested that vitamin $\mathrm{D}$ is an important envir- onmental factor that affects the prevalence of autoimmune syndromes via modulation of immune system. Therefore, it has been suggested that vitamin D deficiency plays a role in the pathogenesis of systemic autoimmune diseases [7]. Both preclinical and clinical studies have provided evidence implying that vitamin D deficiency can cause an increase in the prevalence of systemic lupus erythematosus, asthma, rheumatoid arthritis, systemic vasculitis and antiphospholipid syndrome [8].

Platelet indices are markers that reflect systemic inflammatory response and activity/severity in many diseases. It has been shown that platelet indices have diagnostic value in certain inflammatory and autoimmune disease [9]. The leukopenia or lymphopenia are used to 
describe disease activity in the Sjögren's Syndrome Damage Index (SSDI) [10, 11]. However, any blood count parameters that can be used for patients without Sjögren's Syndrome disease activity for co-diagnosis have not been proposed until now. To best of our knowledge, there is no study reporting relationship between vitamin D levels and platelet indices, namely, PDW, MPW, PCT and PLR, in the literature. From this point of view, it was aimed to evaluate plasma vitamin D levels and its relationship with platelet indices in association with Sjögren's disease.

\section{MATERIALS AND METHODS}

\section{Study design}

This study was conducted at departments of clinical biochemistry and internal medicine, health science University, Kayseri City Training and Research Hospital (Turkey). The study was approved by Local Ethics Committee. The pSS diagnosis was made in department of rheumatology based on validated American-European Consensus Group Classification Criteria [12].

Originally, 289 patients were recruited to the study from rheumatology outpatient clinic between 2013 and 2016. In all patients recruited, demographic and clinical characteristics including age, gender, joint involvement, sicca symptoms, fatigue, neuropathy and medication were recorded. The exclusion criteria included co-morbid systemic disorders including endocrine diseases, autoimmune disorders, malignancy, liver disease, and presence of non-autoimmune sicca symptoms alone. In addition, patients with primary platelet disorders (autoimmune or acquired thrombocytopenia) causing defective platelet indices were also excluded [13]. Moreover, patients received vitamin D supplement, steroids, anticoagulant or anti-platelet agents within prior 6 months were also excluded. The blood samples for vitamin D level measurements were drawn at maximum sun exposure period (from June to September) to account seasonal effects and standardization.

\section{Laboratory evaluations}

The blood samples were taken into EDTA tubes (Becton Dickinson, Franklin Lakes, NJ) for complete blood count (CBC) and vitamin D measurements. Vitamin D levels, C-reactive protein (CRP), erythrocyte sedimentation rate (ESR) and CBC parameters including platelet count (PLT), neutrophil count $(\mathrm{N})$, lymphocyte count (L), mean platelet volume (MPV), platelet distribution width (PDW), plateletecrit (PCT), and platelet-to-lymphocyte ratio (PLR) were measured simultaneously.

In the study group, parameters routinely used in the differential diagnosis of pSS and similar disorders such as serum anti-Sjögren's syndrome antigen A (SS-A), antiSjögren's syndrome antigen B (SS-B), rheumatoid factor (RF), antinuclear antibody (ANA), anti-double-stranded DNA (anti-dsDNA), ribonucleoprotein antibodies (RNP), anti-Jo-1, Smith antibodies (SM) and anti-sclerosis 70 (anti-Scl70) were recorded. In order to investigate potential relationships at different vitamin D status, patients with pSS were classified in to groups according to different serum vitamin D levels.

$\mathrm{CBC}$ was performed by using $\mathrm{XN}-9000$ automated analyzer (Sysmex Co., Kobe, Japan) via impedance and platelet specific fluorescent staining method [14]. The vitami D levels were measured by using Triple Quadrupole LC-MS analyzer (Thermo Fisher Scientific, USA) via Atmospheric Pressure Chemical Ionization (APCI) method. During vitamin D assays, a hexadeuteriumlabeled internal standard (Chromsystem) a Mass Check brand of control, a multi-level calibrator and a mobile phase were used. Limit of detection and coefficient of variation, are $<3.75 \mathrm{ng} / \mathrm{mL}$ and $<6 \%$ in $\mathrm{LC}-\mathrm{MS} / \mathrm{MS}$ method, accepted as reference assay for vitamin D measurements [15]. ESR was determined by using Micro Test-1 (Alifax S.P.A, Padova, Italy) analyzer [16]. CRP and RF levels were measured by using Dade Behring BNII analyzer (Siemens Healthcare Diagnostics Inc., USA) via nephelometric method [17]. ANA, SS-A, SS-B, Anti Ds-DNA, Anti Jo-1, SM, Anti-Scl70 and RNP analyses were performed by indirect immunofluorescence (IIF), ELISA 
and flow cytometry [18].

\section{Statistical analysis}

The Shapiro Wilk test was used to evaluate normal distribution of data. Continuous variables were presented as Mean $\pm S D$. Paired t test was used to compare the continuous variables with normal distribution between matched data set. Pearson's correlation coefficient test was used to measure the strength of a linear association between vitamin $D$ related variables. ANOVA analysis was used to compare mean values among several groups. A $P$ value $<0.05$ was considered as statistically significant. A conditional univariate and multivariate linear regression model was used to determine platelet distribution width, vitamin D and other platelet covariates associated with pSS. For PDW and PCT, receiver characteristic curve analysis (ROC) was performed to calculate the optimal cut-off values. Analyses were performed using commercial software (SPSS version 18.0, SPSS Inc., Chicago, IL, USA) The power analysis was performed (by http://clincalc. $\mathrm{com} /$ stats/samplesize.aspx program) to determine sample size with sufficient statistical power to detect a treatment effect.

\section{RESULTS}

\section{Characteristics of study and control groups}

This analytical cross-sectional study included 132 patients with pSS (3 men, 129 women; mean age: 52 years, range: 40.7 63.3 years) recruited from rheumatology outpatient clinic between 2013 and 2016 and 129 ageand gender-matched healthy controls (3 men, 126 women; mean age: 51.6 years; range: $39.8 \sim 64.7$ years. A total of twenty-eight patients were excluded from study due to these follow exclusion criteria: inability to obtain informed consent $(\mathrm{N}=3)$, incomplete laboratory data $(\mathrm{N}=13)$, malignancy $(\mathrm{N}=2)$, platelet disorder $(\mathrm{N}=1)$, other autoimmune disorder $(\mathrm{N}=6)$, use of anticoagulant or anti-platelet agents $(\mathrm{N}=3)$. The power analysis was performed to determine sample size that could provide 95\% power at alpha level of 0.05 (http://biostat.mc. vanderbilt.edu/twiki/bin/view/Main/ PowerSampleSize).

There was no significant difference in N, L, PLT, MPV and ESR values between study and control groups. The PDW was found to be significantly higher in study group than controls $(15.58 \pm 2.7 \mathrm{fL}$ vs. $12.7 \pm 2.41 \mathrm{fL})$ while no significant difference was found in PCT levels between study and control groups ( $0.279 \pm 0.071$ vs. $0.320 \pm 0.110)$. No significant difference was detected in CPR levels between study and control groups while vitamin levels were significantly lower in patients with pSS than controls $(21 \pm 15.7 \mathrm{ng} / \mathrm{mL}$ vs. $29.7 \pm 15.2 \mathrm{ng} / \mathrm{mL} ; P<0.05)$. In addition, $\mathrm{RF}$ values were significantly higher in patients with pSS than controls $(14.02 \pm 11.09 \mathrm{IU} / \mathrm{mL}$ vs. $3.58 \pm 3.26 \mathrm{IU} / \mathrm{mL} ; P<0.05)$. RF was found to be negatively correlated with vitamin $\mathrm{D} \quad\left(P<0.001, \quad \mathrm{r}_{\mathrm{s}}=-0.681\right)$,

Table 1. The status of hematologic parameters by groups

\begin{tabular}{lcccc}
\hline \multicolumn{1}{c}{ Parameters } & $\begin{array}{c}\text { PSS patients } \\
\text { Mean } \pm \mathrm{SD}(\mathrm{N}=132)\end{array}$ & $\begin{array}{c}\text { Healthy controls } \\
\text { Mean } \pm \mathrm{SD}(\mathrm{N}=129)\end{array}$ & Reference ranges & $P$ values \\
\hline Vitamin $\mathrm{D}(\mathrm{ng} / \mathrm{mL})$ & $21.0 \pm 15.7$ & $29.7 \pm 15.2$ & $>30$ & $<0.05$ \\
CRP $(\mathrm{mg} / \mathrm{L})$ & $6.53 \pm 5.25$ & $5.25 \pm 4.73$ & $0 \sim 5$ & $\mathrm{NS}$ \\
ESR $(\mathrm{mm} / \mathrm{h})$ & $15.25 \pm 4.6$ & $12.17 \pm 6.87$ & $0 \sim 20$ & $\mathrm{NS}$ \\
RF $(\mathrm{IU} / \mathrm{mL})$ & $14.02 \pm 11.09$ & $3.58 \pm 3.26$ & $0 \sim 14$ & $<0.05$ \\
Platelet $\left(\times 10^{3} / \mu \mathrm{L}\right)$ & $266 \pm 53.4$ & $287.2 \pm 72.97$ & $150 \sim 450$ & $\mathrm{NS}$ \\
MPV $(\mathrm{fL})$ & $9.6 \pm 1.71$ & $10.2 \pm 2.89$ & $9 \sim 12$ & $\mathrm{NS}$ \\
PDW (fL) & $15.58 \pm 2.7$ & $12.7 \pm 2.41$ & $10 \sim 16$ & 0.012 \\
PCT $(\%)$ & $0.279 \pm 0.071$ & $0.320 \pm 0.110$ & $0.17 \sim 0.4$ & 0.049 \\
PLR & $142.047 \pm 58.23$ & $128.098 \pm 42.51$ & - & $<0.001$ \\
Lymphocyte $\left(\times 10^{3} / \mu \mathrm{L}\right)$ & $2.14 \pm 0.52$ & $2.53 \pm 0.68$ & $0.8 \sim 3.4$ & $\mathrm{NS}$ \\
Neutrophil $\left(\times 10^{3} / \mu \mathrm{L}\right)$ & $4.33 \pm 1.14$ & $4.12 \pm 2.12$ & $1.8 \sim 7.5$ & $\mathrm{NS}$ \\
\hline
\end{tabular}

Abbreviations: CRP, C-reactive protein; ESR, erythrocyte sedimentation rate; RF, Romatoid factor; MPV, mean platelet volume; PDW, Platelet distribution width; PCT, Plateletecrit; PLR, platelet-to-lymphocyte ratio; NS, no significance. 
plateletecrit $\left(P<0.001, \mathrm{r}_{\mathrm{s}}=0.664\right)$ and platelet counts $(P<$ $\left.0.004, r_{s}=0.600\right)$ in patients with pSS. No significant correlation was found between vitamin D levels and CRP or ESR in patients with pSS (Table 1).

\section{Study group characteristics}

In pSS group, only 3 patients were male. Mean age was $52 \pm 11.26$ years in the study group. Disease duration was estimated as $40 \pm 21$ months (median, min-max: 36.5 36.127). Mean time from diagnosis was found to be $19 \pm 18$ months (median, min-max: 18.5 19.70). In the study group, sicca symptoms were present in $94 \%$ whereas joint

Table 2. Clinical characteristics of patients with Sjögren's syndrome

\begin{tabular}{lc}
\hline \multicolumn{1}{c}{ Characteristics } & Mean (min-max or \%) \\
\hline Age (years) & $52(28 \sim 72)$ \\
Gender (female) (N(\%)) & $129(3)$ \\
Cigarette (yes/no) & $29 / 103$ \\
Disease duration (months) & $40(38.6 \sim 144.36)$ \\
Duration of diagnosis (months) & $15(8.5 \sim 50.19)$ \\
Articular involvement (N(\%)) & $122(93)$ \\
Sicca symptoms (N(\%)) & $124(94)$ \\
Change in fatigue (N(\%)) & $72(67)$ \\
Neuropathy-lymphoma (N(\%)) & $1(0.8)$ \\
Symptoms on diagnosis & \\
Sicca (N(\%)) & $118 \sim 89(75.4)$ \\
Joint (N(\%)) & $112 \sim 85(75.8)$ \\
Other (N(\%)) & $20(15-75)$ \\
Treatment & $118(89)$ \\
Hdyroxychloroqine (N(\%)) & $131(79)$ \\
Hdyroxychloroqine (N(\%)) & $3(2.2)$ \\
Methotrexate (N(\%)) &
\end{tabular}

Table 3. Autoantibody profiling and frequency of autoantibodies in patients with pSS

\begin{tabular}{lcc}
\hline \multicolumn{1}{c}{ Parameters } & Total & No. of positive/negative (FO) \\
\hline SS-A & 132 & $103 / 29(78)$ \\
SS-B & 132 & $84 / 48(64)$ \\
Anti Ds-DNA & 100 & $15 / 85(15)$ \\
RNP & 100 & $3 / 97(3)$ \\
Anti-Jo & 100 & $98 / 2(98)$ \\
ANA & 100 & $91 / 9(91)$ \\
SM & 100 & $1 / 99(1)$ \\
Scl70 & 100 & $4 / 96(4)$ \\
SGB & 64 & $61 / 3(95)$ \\
\hline
\end{tabular}

Abbreviations: FO, Frequency of occurrence(\%); SS-A, anti-Sjögren's Syndrome antigen A; SS-B, anti-Sjögren's Syndrome antigen B; Anti Ds-DNA, Anti-double stranded DNA; RNP, Anti-RNP antibody; Anti-Jo, antihistidyl ANA, antinuclear antibody; SM, Smith antigen; Scl70, Anti-Scl70 antigen; SGB, salivary gland biopsy. involvement in 93\% and fatigue in 67\% (Table 2). Salivary gland biopsy was performed in 64 patients, revealing diagnostic findings in 61 patients; however, it was non-diagnostic in remaining 3 patients. When autoantibody profile was considered, it was seen that SS-A and SS-B auto-antibodies were available in all patients. Positive SS-A and SS-B results were found in 78\% and 64\% of patients, respectively. Anti-DsDNA, RNP, anti-Jo, ANA, SM and Scl70 antibodies were found to be present in 15\%, $3 \%, 98 \%, 91 \%, 1 \%$ and $4 \%$, respectively (Table 3 ).

In correlation analyses, a significant, negative correlation was found between vitamin D and RF $\left(\mathrm{r}_{\mathrm{s}}=-0.681, P<\right.$ $0.005)$ while a weak correlation was detected between low vitamin D levels and SSDI scores $\left(\mathrm{r}_{\mathrm{s}}=-0.126, P<0.05\right)$. Further, the vitamin D correlations were revealed with some platelet indices in patients with pSS (for PDW, $\mathrm{r}_{\mathrm{s}}=$ $-0.408, P<0.01$ and for PCT $\mathrm{r}_{\mathrm{s}}=0.646, P<0.001$; Table 4).

The patients with pSS were stratified into 3 groups according to vitamin D levels: group I (severe deficiency) (N=34), group II (deficiency) $(\mathrm{N}=46)$ and group III (sufficient) (N=52). Mean vitamin D levels were $6.8 \pm 1.8$ $\mathrm{ng} / \mathrm{mL}, 16.3 \pm 1.7 \mathrm{ng} / \mathrm{mL}$ and $21 \pm 3.2 \mathrm{ng} / \mathrm{mL}$ in group I, II

Table 4. Vitamin D correlations with some demographic and hematologic parameters of patients with primer Sjögren's syndrome

\begin{tabular}{lcc}
\hline \multicolumn{1}{c}{ Parameters } & $\begin{array}{c}\text { Correlation } \\
\text { coefficient }(\mathrm{rs})\end{array}$ & $P$ value \\
\hline SSDI & $-0.126^{*}$ & 0.047 \\
Platelet $\left(\times 10^{3} / \mu \mathrm{L}\right)$ & 0.414 & 0.075 \\
MPV $(\mathrm{fL})$ & 0.419 & 0.074 \\
PDW $(\mathrm{fL})$ & $-0.408^{*}$ & 0.012 \\
PCT $(\%)$ & $0.646^{\star *}$ & $<0.001$ \\
PLR & 0.103 & 0.103 \\
Lymphocyte $\left(\times 10^{3} / \mu \mathrm{L}\right)$ & 0.045 & 0.617 \\
Neutrophil $\left(\times 10^{3} / \mu \mathrm{L}\right)$ & -0.061 & 0.499 \\
Monocyte & 0.102 & 0.262 \\
Eosinophils & 0.015 & 0.869 \\
Basophil & -0.092 & 0.309 \\
ESR & 0.097 & 0.495 \\
RF & $-0.681^{\star *}$ & 0.004 \\
Eosinophils & 0.015 & 0.869 \\
\hline
\end{tabular}

${ }^{* *}$ Correlation is significant at the 0.01 level (2-tailed), ${ }^{*}$ Correlation is significant at the 0.05 level (2-tailed). Abbreviations: SSDI, Sjögren's Syndrome Damage Index; MPV, Mean platelet volume; PDW, Platelet distribution width; PCT, Plateletecrit; PLR, platelet-to-lymphocyte ratio; ESR, erythrocyte sedimentation rate; RF, Romatoid factor. 
and II, respectively. Mean PDW and PCT values were found to be $17.48 \pm 1.74$ and $0.259 \pm 0.491$ in group I; $16.3 \pm 1.41$ and $0.275 \pm 0.028$ in group II; and $15.1 \pm 1.36$ and $0.278 \pm$ 0.324 in group III, respectively. There was a significant difference in PDW between Group I and III (Figure 1 and Table 5).

Univariate and multivariate linear regression analysis was performed. In multivariate linear regression analysis, PDW was a dependent variable and independent variables was adjusted as age, sex, duration of disease, CRP, ESR, PCT, PLR, vitamin D. In the multivariate regression, parameters with significant effect on PDW were as follows: vitamin $\mathrm{D}(\beta=-0.373 ; \mathrm{t}=-2.626$; sig. $=0.013)$ and platelecrit $(\beta=-0.308 ; t=-2.13$; sig. $=0.040)$.

The ROC curves were constructed for PDW and PCT according to vitamin D level in patients with pSS. Figure 2

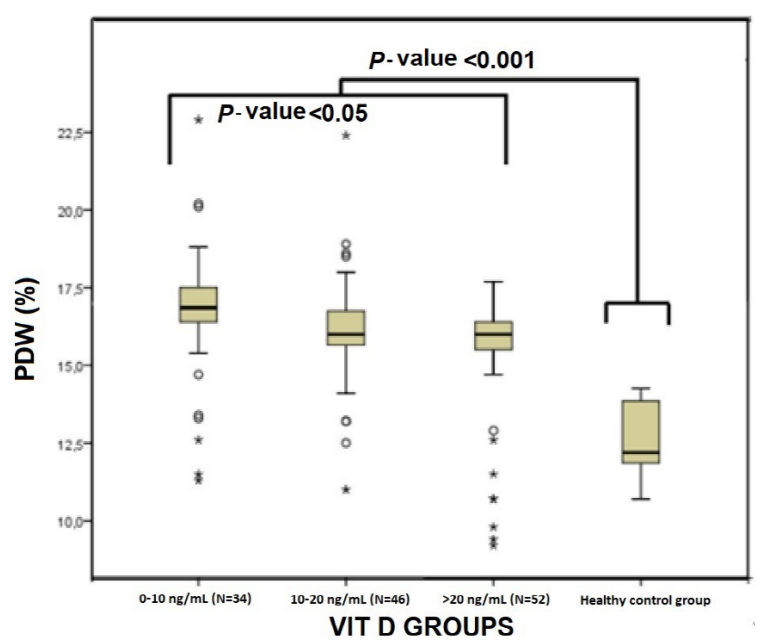

Figure 1. Subgroup's graph of vitamin D and platelet distribution width. presents parameters describing ROC curves. The cut-off points estimated as 12.53 and 0.29 for PCT and PDW. The AUC, sensitivity and specificity were $0.921,90 \%$ and $85 \%$ for PDW and $0.660,68 \%$ and 55\% for PCT, respectively.

\section{Control group characteristics}

The control group was selected from hospital staff and relatives of patients. The age- and sex-matched controls without history of systemic disease and/or chronic medication were enrolled to the study. In the control group, no significant relationship was found between vitamin D levels and platelet. The vitamin D levels were consistent to those reported for Turkish population (Mean \pm SD: 29.7 \pm 15.2 ) [23].

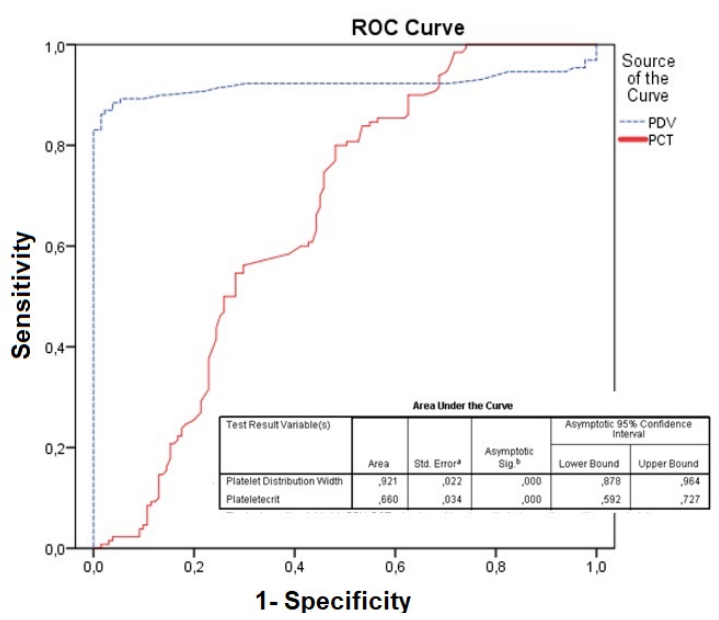

Figure 2. Receiver operating characteristic analysis of PDW, and PCT that predict pSS.

Table 5. The status of hematologic parameters by groups

\begin{tabular}{|c|c|c|c|c|}
\hline Parameters & $\begin{array}{c}\text { Group I } \\
\text { Vitamin D } \\
<10 \mathrm{ng} / \mathrm{mL} \\
\text { Mean } \pm \text { SD } \\
(\mathrm{N}=34))\end{array}$ & $\begin{array}{c}\text { Group II } \\
\text { Vitamin D } \\
10 \sim 20 \mathrm{ng} / \mathrm{mL} \\
\text { Mean } \pm \text { SD } \\
(\mathrm{N}=46)\end{array}$ & $\begin{array}{c}\text { Group III } \\
\text { Vitamin D } \\
>20 \mathrm{ng} / \mathrm{mL} \\
\text { Mean } \pm \text { SD } \\
(\mathrm{N}=52)\end{array}$ & $P$ values \\
\hline Vitamin $\mathrm{D}(\mathrm{ng} / \mathrm{mL})$ & $6.81 \pm 1.8^{\mathrm{a}, \mathrm{b}}$ & $16.3 \pm 1.7^{\mathrm{a}, \mathrm{c}}$ & $21 \pm 3.2^{b, c}$ & $<0.001$ \\
\hline PDW (fL) & $17.48 \pm 1.74^{\mathrm{a}}$ & $16.3 \pm 1.41$ & $15.1 \pm 1.36^{c}$ & 0.024 \\
\hline PCT (\%) & $0.259 \pm 0.491$ & $0.275 \pm 0.028$ & $0.278 \pm 0.324$ & 0.028 \\
\hline
\end{tabular}

a Shows the groups which differs according to the Group III.

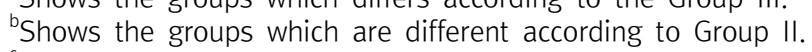

'Shows the groups which differs according to the Group I.

Abbreviations: SD, standard deviation; PDW, Platelet distribution width; PCT, Plateletecrit. 


\section{DISCUSSION}

To best of our knowledge, this is first study on relationships between vitamin $\mathrm{D}$ status and platelet indices, namely PDW, MPV, PLR, and PCT, in patients with pSS. This study has several findings. Firstly, vitamin D levels were decreased significantly in patients with pSS. There are studies reporting different levels of vitamin $D$ in patients with pSS [19, 20]. Our findings were consistent with the study conducted in Turkish population pSS patients [21]. Although our study was conducted between March and August, which is considered as a period with maximal sun exposure, vitamin D levels were low both in patient and the healthy control group. The sun exposure is crucial for vitamin D synthesis. In this context, the short summer season, the continental climate of the city where study was conducted, and the traditional clothing style might lead to reduced sun exposure. Further, genetic polymorphism of vitamin D receptors might explain our results, deserving further attention. In addition, great progress has been achieved on the cellular and molecular mechanisms underlying the effects of vitamin D on pSS.

Secondly, there was significant negative correlation between vitamin D levels and PDW whereas a significant positive correlation between vitamin D levels and PCT. Mean platelet volume (MPV) and platelet distribution width (PDW) are biomarkers of platelet activation [22]. The PDW is an indicator of variation in platelet size [23]. Platelet activation causes morphologic changes in platelets such as formation of spherical shape and pseudopodia. The increased number and varying size of pseudopodia in platelets presumably affect platelet distribution width [24]. The PDW quantifies variability in platelet size, which increases during platelet activation. It is used to identify larger platelet fraction which are more active in both enzymatic and metabolic manner. It is proposed that PDW is a more important marker than MPV regarding platelet [25]. Platelet activation in inflammatory diseases is well known [26]. According to our findings, PDW, a platelet activation marker, seemed to be a more specific indicator of platelet activation than MPV, since during platelet distention caused by platelet activation, in pSS as a rheumatologic inflammatory disease.

In this current work, platelets showed a correlation with vitamin D levels $>20 \mathrm{ng} / \mathrm{mL}$ and PDW $(P<0.01)$ was found to show a strong, negative correlation with vitamin D levels in pSS. Plateletecrit is total mass of platelets [27]. There is a direct relationship between MPV and PDW; both generally alter in the same course. However, there are also contrary reports about the relationship between platelet volume and counts in the literature, suggesting that these parameters are affected by different mechanisms [28]. In our study, no influence of vitamin D level was observed on platelet count and MPV while PDW and PCT were correlated with vitamin D status of pSS patients. In a study, it was shown that platelet count and size fluctuations are due to the periodic increase of platelet destruction, as well as periodic failure of platelet product in the pSS patients [29]. The platelet index changes in our study may also compatible with disease specific periodic platelet destructions.

There is evidence indicating that platelet count and size is influenced by molecular processes controlling [30]. However, genetic polymorphisms together with lifestyle factors account for $<20 \%$ of natural variation effect to platelets [31]. That is the reason why comparisons between groups were matched for age, gender and lifestyle factors. Patients with history of thrombotic event and those diagnosed autoimmune and acquired thrombocytopenia were excluded in order to minimize this effect. Unfortunately, we are unable to investigate gene functions that control the megakaryopoiesis and platelet formation process due to technical limitations. This may comprise a limitation in our work.

In the current study, other limitations included the lack of assessment of sunlight exposure and evaluation of mobility status. In addition, we did not compare vitamin D levels and clinical (i.e., peripheral neuropathy, skin vasculitis, palpable purpura) and laboratory (i.e., gamma globulin levels and C3, C4) findings in patients with pSS. We suggested that the increase in PDW and decrease in PCT may be related to autoimmune inflammation triggered 
by vitamin D deficiency in Sjögren's patients. Therefore, we suggest that platelet indices, particularly PCT and PDW which are easily accessible and reliable in the context of pSS disease activity, may be assessed in patients with pSS. The diagnosis of progressive activation of pSS can help managing these diseases successfully. These platelet parameters, which have been suggested to be related to vitamin D, may be assessed as ancillary diagnostic laboratory parameters.

The vitamin D supplementation in the treatment of pSS appears as a promising approach. Multi-center and larger (comparative, pre- and post-treatment) studies are need to evaluate relationship between vitamin D and platelet indices on the ethiopathogenesis of pSS. The combined assessment of platelet indices with vitamin D could predict activation of inflammation more efficiently in pSS. Therefore, disease-specific and ethnicity/regional/racespecific definitions of vitamin D deficiency should have to be established in future studies in order to define goals of vitamin D replacement in patients with pSS patients.

Acknowledgements: The Institutional Scientific Review Board of Kayseri Training and Research Hospital approved this study. Prior to the study, institutional scientific research committee permission was obtained to review the clinical records of patients. Ethical approval for this study (Decision number: 01/04/2016-96681246/04) was provided by the Ethical Committee Erciyes University, Medical Faculty, Kayseri, Turkey. Personal identifiers were entirely removed and the records were analyzed anonymously. Informed consent was obtained from the parents of all the patients using the data.

Conflict of interest: None

Author's information (Position): Günay $\mathrm{NE}^{1}$, M.D.; Buğday İ $^{2}$, M.D.; Akal ın T ${ }^{3}$, M.D.

\section{REFERENCES}

1. Moutsopoulos HM. Sjögren's syndrome: autoimmune epithelitis. Clin Immunol Immunopathol. 1994;72:162-165.

2. Birlik M, Akar S, Gurler O, Sari I, Birlik B, Sarioglu S, et al. Prevalence of primary Sjogren's syndrome in Turkey: a pop- ulation-based epidemiological study. Int J Clin Pract. 2009; 63:954-961. https://doi.org/10.1111/j.1742-1241.2008.01749.x.

3. Kabasakal Y, Kitapcioglu G, Turk T, Oder G, Durusoy R, Mete $\mathrm{N}$, et al. The prevalence of Sjögren's syndrome in adult women. Scand J Rheumatol. 2006;35:379-383.

4. Düzgün N, Şahin M, Genç Y, Tutkak H. Antinucleosome antibodies and systemic lupus erythematosus. Ann N Y Acad Sci. 2007;1109:421-428.

5. Akkoc N, Akar S. Epidemiology of rheumatoid arthritis in Turkey. Clin Rheumatol. 2006;25:560-561.

6. Altieri B, Muscogiuri G, Barrea L, Mathieu C, Vallone CV, Mascitelli L, at al. Does vitamin D play a role in autoimmune endocrine disorders? A proof of concept. Rev Endocr Metab Disord. 2017;18:335-346. https://doi.org/10.1007/s11154-0169405-9.

7. Cantorna MT. Vitamin D and autoimmunity: is vitamin D status an environmental factor affecting autoimmune disease prevalence? Proc Soc Exp Biol Med. 2000;223:230-233.

8. Cutolo M. Vitamin D or hormone D deficiency in autoimmune rheumatic diseases, including undifferentiated connective tissue disease. Arthritis Res Ther. 2008;10:123. https://doi.org/ 10.1186/ar2552.

9. Bath PM, Butterworth RJ. Platelet size: measurement, physiology and vascular disease. Blood Coagul Fibrinolysis. 1996;7: 157-161.

10. Barry RJ, Sutcliffe N, Isenberg DA, Price E, Goldblatt F, Adler M, et al. The Sjogren's syndrome damage index-a damage index for use in clinical trials and observational studies in primary Sjögren's syndrome. Rheumatology (Oxford). 2008;47:11931198. https://doi.org/10.1093/rheumatology/ken164.

11. Bowman SJ, Sutcliffe N, Isenberg DA, Goldblatt F, Adler M, Price E, et al. Sjögren's systemic clinical activity index (SCAI)-a systemic disease activity measure for use in clinical trials in primary Sjögren's syndrome. Rheumatology (Oxford). 2007;46: 1845-1851. https://doi.org/10.1093/rheumatology/kem280.

12. Vitali C, Palombi G, Baldini C, Benucci M, Bombardieri S, Covelli M, et al. Sjogren's syndrome Disease Damage Index and disease activity index: scoring systems for the assessment of disease damage and disease activity in Sjögren's syndrome, derived from an analysis of a cohort of Italian patients. Arthritis Rheum. 2007;56:2223-2231. https://doi.org/10.1002/art.22658.

13. Giovanetti TV, do Nascimento AJ, de paula JP. Platelet indices: laboratory and clinical applications. Rev Bras Hematol Hemoter. 2011;33:164-165. https://doi.org/10.5581/1516-8484.20110040.

14. Harrison P, Ault KA, Chapman S, Charie L, Davis B, Fujimoto K, et al. An interlaboratory study of a candidate reference method for platelet counting. Am J Clin Pathol. 2001;115:448-459. https://doi.org/10.1309/91PR-E4G6-XBAF-N8DY.

15. Jenkinson C, Taylor AE, Hassan-Smith ZK, Adams JS, Stewart PM, Hewison M, et al. High throughput LC-MS/MS method for the simultaneous analysis of multiple vitamin $\mathrm{D}$ analytes in serum. J Chromatogr B Analyt Technol Biomed Life Sci. 2016; 1014:56-63. https://doi.org/10.1016/j.jchromb.2016.01.049.

16. Hardeman MR, Levitus M, Pelliccia A, Bouman AA. Test 1 analyser for determination of ESR. 1. Practical evaluation and comparison with the Westergren technique. Scand J Clin Lab Invest. 2010;70:21-25. https://doi.org/10.3109/00365510903365952. 
17. Drieghe SA, Alsaadi H, Tugirimana PL, Delanghe JR. A new high-sensitive nephelometric method for assaying serum C-reactive protein based on phosphocholine interaction. Clin Chem Lab Med. 2014;52:861-867. https://doi.org/10.1515/cclm2013-0669.

18. Eissfeller P, Sticherling M, Scholz D, Hennig K, Lüttich T, Motz $\mathrm{M}$, et al. Comparison of different test systems for simultaneous autoantibody detection in connective tissue diseases. Ann N Y Acad Sci. 2005;1050:327-339. https://doi.org/10.1196/annals. 1313.035.

19. Szodoray P, Horvath IF, Papp G, Barath S, Gyimesi E, Csathy L, et al. The immunoregulatory role of vitamins A, D and E inpatients with primary Sjögren's syndrome. Rheumatol (Oxford). 2010;49:211-217. https://doi.org/10.1093/rheumatology/ zkep374.

20. Agmon-Levin N1, Kivity S, Tzioufas AG, López Hoyos M, Rozman B, Efes I, et al. Low levels of vitamin-D are associated with neuropathy and lymphoma among patients with Sjogren's syndrome. J Autoimmun. 2012;39:234-239. https://doi.org/ 10.1016/j.jaut.2012.05.018.

21. Erten Ş, Şahin A, Altunoğlu A, Gemcioğlu E, Koca C. Comparison of plasma vitamin D levels in patients with Sjogren's syndrome and healthy subjects. Int J Rheum Dis. 2015;18:70-75. https://doi.org/10.1111/1756-185X.12298.

22. Margetic S. Inflammation and homeostasis. Biochem Med (Zagreb). 2012;22:49-62.

23. Farias MG, Schunck EG, Dal Bó S, de Castro SM. Definition of reference ranges for the platelet distribution width (PDW): a local need. Clin Chem Lab Med. 2010;48:255-257. https://doi.org/10.1515/CCLM.2010.035.

24. Kowara M, Grodecki K, Huczek Z, Puchta D, Paczwa K, Rymuza $\mathrm{B}$, et al. Platelet distribution width predicts left ventricular dysfunction in patients with acute coronary syndromes treated with percutaneous coronary intervention. Kardiol Pol. 2017; 75:42-47. https://doi.org/10.5603/KP.a2016.0137.

25. Vagdatli E, Gournari E, Lazaridou E, Katsiborilia E, Tsikopoulou F, Labrianou I. Platelet distribution width; a simple, practical and specific marker of activation of coagulation. Hippokratia. 2010;14:28-32.

26. Işık M, Şahin H, Hüseyin E. New platelet indices as inflammatory parameters for patients with rheumatoid arthritis. Eur J Rheumatol. 2014;1:144-146. https://doi.org/10.5152/ eurjrheumatol.2014.140023.

27. Fan Z, Pan J, Zhang Y, Wang Z, Zhu M, Yang B. Mean platelet volume and platelet distribution width as markers in the diagnosis of acute gangrenous appendicitis. Dis Markers. 2015; 2015:542013. https://doi.org/10.1155/2015/542013.

28. Budak YU, Polat M, Huysal K. The use of platelet indices, plateletecrit, mean platelet volume and platelet distribution width in emergency non-traumatic abdominal surgery: a systematic review. Biochem Med (Zagreb). 2016;26:178-193. https://doi.org/10.11613/BM.2016.020.

29. Yamauchi N, Muramatsu H, Inomata H, Numata T, Nozawa E, Nishino M, et al. Cyclic thrombocytopenia complicated with Sjögren syndrome and the mechanism of periodic platelet count fluctuation. Rinsho Ketsueki. 2008;49:658-663.

30. Gieger C, Radhakrishnan A, Cvejic A, Tang W, Porcu E, Pistis G, et al. New gene functions in megakaryopoiesis and platelet formation. Nature. 2011;480:201-208. https://doi.org/10.1038/ nature10659.

31. Panova-Noeva M, Schulz A, Hermanns MI, Grossmann V, Pefani E, Spronk HM, et al. Sex-specific differences in genetic and nongenetic determinants of mean platelet volume: results from the Gutenberg health study. Blood. 2016;127:251-259. https:// doi.org/10.1182/blood-2015-07-660308. 